\title{
Comparative Efficacy of Bio-Pesticide and Synthetic Agrochemicals on Control of Helicoverpa armigera Larvae on Chickpea
}

\author{
Taimur Ahmad 1,*, Rasool Khan ${ }^{1}$, Tariq Nawaz Khattak², Ayaz Khan ${ }^{1}$ and Ihsan ullah² \\ ${ }^{1}$ Institute of Chemical Sciences, University of Peshawar, Peshawar, Pakistan \\ ${ }^{2}$ Nuclear Institute for Food and Agriculture (NIFA), Peshawar, Pakistan
}

\begin{abstract}
The comparative efficacy of neem as bio-pesticides and synthetic agrochemicals against the larvae of Helicoverpa armigera was carried out during 2016-2017. The experiment was performed using RCBD and consisted of a total of six treatments including the control with four replicates. The results indicated that the synthetic insecticide emamactin was found to be superior in controlling the larval population of pod borer with a \% reduction of 63 and 88 after $1^{\text {st }}$ and $2^{\text {nd }}$ application respectively followed by chlorpyrifos after $2^{\text {nd }}$ application. The neem bio-pesticide showed best results next to emamectin after the first application. The acetamiprid was found to be least effective in controlling the pod borer larvae.

$\begin{array}{lll}\text { Keywords } & \text { *Address of Correspondence } & \text { Article info. } \\ \begin{array}{l}\text { Bio-pesticide, pod borer, neem oil, } \\ \text { chickpea, adjuvant. }\end{array} & \text { taimurjf@yahoo.com } & \text { Received: April 13, 2018 } \\ & & \text { Accepted: October 23, } 2018\end{array}$

Cite this article: Ahmad T, Khan R, Khattak TN, Khan A, Ullah I. Comparative Efficacy of Bio-

Funding Source: Nil

Pesticide and Synthetic Agrochemicals on Control of Helicoverpa armigera Larvae on Chickpea.

Conflict of Interest: Nil

RADS J. Biol. Res. Appl. Sci. 2018; 9(2): 75-81.

This is an Open Access article distributed under the terms of the Creative Commons Attribution License (http://creativecommons.org/licenses/by/4.0), which permits unrestricted use, distribution, and reproduction in any medium, provided the original work is properly cited.

\section{INTRODUCTION}

The chickpea is attacked by Helicoverpa armigera which is commonly known as gram pod borer and is the main pest of the chickpea ${ }^{1,2}$. This pest causes a great loss in chickpea ${ }^{3}$. In most of the chickpea producing area, the gram pod borer has been reported to have developed resistance to most of the commonly used pesticides ${ }^{4}$. The Helicoverpa armigera is a polyphagous insect and attacks more than 200 species of almost 45 crops throughout the world 5 . The total annual yield loss of different crops by Helicoverpa armigera has been reported to be a worth of 2 billion US dollars ${ }^{6}$.

The initial stage of the life cycle, larval stage control is important to prevent the severe damage and yield loss ${ }^{7,8}$. Various control measures have been adopted to control or minimize the attack of chickpea pod borer ${ }^{9}$. Synthetic

pesticides are commonly used to control the pests. But the extensive use of synthetic pesticides has created several problems including mammalian toxicity, destruction of useful insects, resistance development in pests etc. ${ }^{10}$. Plant extracts are suitable and safe alternatives to toxic synthetic pesticides. The neem oil is obtained from Azadirachta Indica and possesses insecticide activities against a wide range of insect pests $^{11-13}$. The active ingredient in the neem oil is Azadirachtin. The neem oil is target specific and insects cannot develop resistance to it. The neem oil is not soluble in water and should be emulsified first before use. Usually, surf or detergents are used to emulsify the neem oil. This surf contains synthetic chemicals which may alter the chemistry of plants. Furthermore, the emulsified oil is made only when needed and cannot be stored for a long
\end{abstract}


time. We have developed an adjuvant at the Nuclear Institute for Food and Agriculture NIFA, Peshawar. This adjuvant is designated as NIFA-1 and acts as emulsifier, spreader, and sticker. We have observed that the neem oil emulsified with NIFA-1 adjuvant has shown pesticide activity after two years of storage. The total cost for the production of this adjuvant in Rs.200 per liter.

\section{MATERIAL AND METHOD}

\section{Experimental Design}

The experiment was carried out on chickpea variety NIFA2005 during 2016-2017. The field was ploughed twice for seed sowing and the weeds and other grasses were also removed from the soil. The plot was divided into twentyfour 24 subplots. The space between the rows was $38 \mathrm{~cm}$ and the distance between the plants was $10 \mathrm{~cm}$. There were a total of six treatments including a control with four replications. Seven plants were randomly selected in each subplot for the observation of chickpea pod borer larvae. The design used in this experiment was RCBD. The experimental data were analyzed by statistics 8.1 software. The percent data were subjected to square root transformation for statistical analysis. Mean comparisons for treatment parameters were compared using Tukey's tests at $5 \%$ level of significance.

\section{Application of Insecticides}

The pesticides were applied as a foliar spray with the help of knap sprayer. There were two sprays for each insecticide. The first application was done after the appearance of pod borer larvae and the second was done after one week of the first application. The treatments are shown in the following Table 1.

Table 1: Treatments of insecticides and concentration of dose.

\begin{tabular}{ccc}
\hline Treatments & Pesticides & $\begin{array}{c}\text { The Concentration } \\
\text { of Dose (\%) }\end{array}$ \\
\hline T1 & $\begin{array}{c}\text { Emamectin } \\
\text { benzoate }\end{array}$ & 0.5 \\
\hline T2 & Acetamiprid & 0.5 \\
\hline T3 & Chlorpyrifos & 0.5 \\
\hline T4 & $\begin{array}{c}\text { Bifenthrin+neem } \\
\text { oil+N.A }\end{array}$ & 1 \\
\hline T5 & Neem oil+N.A & 3 \\
\hline T6 & Control & --- \\
\hline
\end{tabular}

Data Collection
The data was collected regarding the larvae of the pod borer. The data was taken by visual count method of the chickpea pod borer. The pretreatment record of the pod borer was noted 24 hours before the treatment and the post-treatment data was taken after one, two and three days of the applications. Seven plants per subplot were selected randomly for the observation of larvae of pod borer. Three distinct stages of the pod borer i.e. neonate, the middle and the fully grown larvae were noted. The percent reduction of larvae was determined by using Abbot Formula developed in 1925. The formula is written as;

$\%$ Reduction $=$ C-T $/ C$ X100. Where,

$\mathrm{C}=$ larvae population in control

$\mathrm{T}=$ larvae population in treatment

The percent pod damage and the percent damage reduction of pod over control are given below ${ }^{14}$.

$$
\begin{array}{cc}
\% \text { Pod damage }=\frac{\text { No. of affected pods }}{\text { Total no. of pods }} \times 100 \\
\begin{array}{c}
\text { \% reduction in pod } \\
\text { damage } \\
\text { Over control }
\end{array} & \begin{array}{l}
\text { Pod damage in control }- \\
\text { Pod damage in treatment }
\end{array} \times 100 \\
\text { Pod damage in control }
\end{array}
$$

The biomass containing the dry chickpea plant was calculated by weighing the chickpea plant at harvest.

\section{RESULTS \& DISCUSSIONS}

\section{First Application of Pesticides}

The data in Table 2 shows the pretreatment and posttreatment larval population of the chickpea pod borer for the first application of the pesticides. It can be seen from the pretreatment data that chickpea plants contain a large number of the pod borer larvae of neonate stage which is the first distinct stage of the pod borer. There was almost the same population of the neonates before treatments in all the subplots. The number of neonates in the case of emamectin and Acetamiprid was 6.2 and 5.8 respectively. The number of neonates was 7.2 and 7.1 in case of chlorpyrifos and bifenthrin +emulsified neem oil combination respectively while the emulsified neem oil and control has a population of 6.5 and 6.8 respectively. The middle stage larval population was 0.3 for emamectin and 0.2 each for chlorpyrifos and neem oil treatment, 
while this middle instar was absent in case of acetamiprid, bifenthrin +emulsified neem oil combination and control treatments respectively. combinations treatment which consists of neem oil and NIFA adjuvant and bifenthrin as a synergist. The last treatment which consists of purely neem oil and NIFA

Table 2: Pretreatment and post-treatment larval population of pod borer after $1^{\text {st }}$ spray.

\begin{tabular}{ccccccccccc}
\hline S. No & \multicolumn{4}{c}{ Larval population (Pretreatment) } & \multicolumn{4}{c}{ Larval population (Post-treatment) } \\
\hline Treatments & $\mathrm{N}$ & $\mathrm{M}$ & $\mathrm{F}$ & Total & Mean & $\mathrm{N}$ & $\mathrm{M}$ & $\mathrm{F}$ & Total & Mean \\
\hline $\mathrm{T} 1$ & $6.2 \pm 1.6 \mathrm{a}$ & $0.3 \pm 0.21 \mathrm{a}$ & $0 \pm 0$ & 6.5 & 2.1 & $5.2 \pm 1.8 \mathrm{bc}$ & $0.5 \pm 0.3 \mathrm{c}$ & $0.1 \pm 0.1 \mathrm{~b}$ & 5.8 & 1.93 \\
\hline $\mathrm{T} 2$ & $5.8 \pm 0.9 \mathrm{a}$ & $0 \pm 0 \mathrm{~b}$ & $0 \pm 0$ & 5.8 & 1.93 & $7.6 \pm 1.2 \mathrm{ab}$ & $0.6 \pm 0.4 \mathrm{c}$ & $0.8 \pm 0.3 \mathrm{a}$ & 9 & 3 \\
\hline $\mathrm{T} 3$ & $7.2 \pm 1.6 \mathrm{a}$ & $0.2 \pm 0.18 \mathrm{ab}$ & $0 \pm 0$ & 7.4 & 2.4 & $5.1 \pm 0.98 \mathrm{bc}$ & $1.6 \pm 0.47 \mathrm{bc}$ & $0.1 \pm 0.08 \mathrm{~b}$ & 6.8 & 2.2 \\
\hline $\mathrm{T} 4$ & $7.1 \pm 1.6 \mathrm{a}$ & $0 \pm 0 \mathrm{~b}$ & $0 \pm 0$ & 7.1 & 2.3 & $3.2 \pm 0.8 \mathrm{c}$ & $2.7 \pm 0.6 \mathrm{~b}$ & $0.2 \pm 0.2 \mathrm{~b}$ & 6.1 & 2.03 \\
\hline T5 & $6.5 \pm 0.9 \mathrm{a}$ & $0.2 \pm 0.14 \mathrm{ab}$ & $0 \pm 0$ & 6.7 & 2.2 & $3.4 \pm 0.6 \mathrm{c}$ & $2.7 \pm 0.4 \mathrm{~b}$ & $0 \pm 0 \mathrm{~b}$ & 6.1 & 2.03 \\
\hline T6 & $6.8 \pm 1.1 \mathrm{a}$ & $0 \pm 0 \mathrm{~b}$ & $0 \pm 0$ & 6.8 & 2.2 & $9.11 \pm 1.7 \mathrm{a}$ & $5.3 \pm 0.9 \mathrm{a}$ & $1.2 \pm 0.3 \mathrm{a}$ & 15.6 & 5.2
\end{tabular}

Where, $\mathrm{N}=$ neonate, $\mathrm{M}=$ =middle and $\mathrm{F}=$ fully grown larval stages respectively

The fully grown instar of the larvae was absent in all the subplots before the application of the 1 st spray. So the pretreatment total larval population of all the three instars of the pod borer larvae in case of emamectin and acetamiprid was 6.5 and 5.8 respectively while chlorpyrifos and bifenthrin +emulsified neem oil combinations have total larval population 7.4 and 7.1 respectively. Total larval population in case of emulsified neem oil and control treatments were 6.7 and 6.8 respectively. The mean value of the three instars of the chickpea pod borer larvae before the treatment were 2.1, 1.93, 2.4, 2.3, 2.2 and 2.2 for emamactin, acetamiprid, chlorpyrifos, bifenthrin + emulsified neem oil combination, emulsified neem oil and control treatments respectively. The post-treatment data shows that emamectin, the treated plot has a neonate instar population of 5.2 per seven plants while the middle instar $(\mathrm{M})$ has a population of 0.5 and 0.1 fully grown instar. The acetamiprid treated plot has neonate instar population of 7.6 per seven plants. In this treatment, the number of middle instar population was 0.6 , while the fully mature instar $(F)$ population was 0.8 . The chlorpyrifos treated plot has a post-treatment neonate population of 5.1 per seven plants. In this treatment, the middle instar $(\mathrm{M})$ has a population of 1.6 and 0.8 population of fully mature $(F)$ instar. The bifenthrin + emulsified neem oil combination treatment has a decline in the neonate instar population with a value of 3.2 per seven plants. The middle instar, (M) and the fully grown instar $(F)$ population were found to be 2.7 and 0.2 respectively in case of bifenthrin +emulsified neem oil adjuvant as emulsifier has a neonate population of 3.4 , while the middle instar larval population was found to be 2.7 and no population of the fully grown instar larva was found. The population of neonates were increased in the case of control and was 9.1 per seven plants. The middle instar of larva was also present in large number as compared to all other treatments and their population was 5.3. Similarly, the full-grown larval instar $(F)$ population was recorded to be 1.2. It can be seen from Table 2. that total larval population in case of emamactin, acetamiprid, chlorpyrifos, bifenthrin + emulsified neem oil combination, emulsified neem oil and control treatments were 5.8, 9, $6.8,6.1,6.1$ and 15.6 respectively while the mean values of all the three larval populations were 1.93, 3, 2.2, 2.03, 2.03 and 5.2 respectively.

\section{Second Application of Pesticides}

The second application of the pesticides was performed after one week of the first application. In this case, the pretreatment data of the chickpea pod borer was also noted one day before the application of the spray and the post-treatment data was taken after one, two and three days of the application. The pretreatment data shows that the number of neonate population was considerably low and was 0.9 in case of ememactin, the middle instar (M) has a population of 0.2 per seven plants while the fully grown instar $(F)$ was still not found. It can be seen from Table 3 that acetamiprid treatment has a neonate instar population of 0.7 and middle instar pod borer population of 0.6 and a fully grown larval population $(F)$ with a value of 0.2 . chlorpyrifos treatment has a neonate population of 
1.6, middle (M) instar population of 0.7 and the fully grown larval population of 0.1 respectively. The neonates, middle and the fully grown pod borer larvae population values were $0.6,1.4$ and 0.3 respectively for bifenthrin + emulsified neem oil combination treatment. The neem oil emulsified with NIFA adjuvant has a neonate population of 0.8 , middle $(M)$ stage larval population of 0.7 and 0.1 population of fully mature instar larva of pod borer. In the case of control, the neonate instar population was 1.4, middle instar population (M) was 1.7 while the fully grown instar has a population of 0.6. The pretreatment total larval populations for emamactin, acetamiprid, chlorpyrifos, bifenthrin + emulsified neem oil combination, emulsified neem oil and control were 1.1, 1.5, 2.8, 2.3, 1.6 and 3.7 respectively and the mean values of this larval instar were $0.36,0.5,0.9,0.76,0.53$ and 1.23 respectively. mean was 2.96 for acetamiprid. The chlorpyrifos treated plants have a neonate instar population of 0.2 after the application of the $2^{\text {nd }}$ spray. The middle larval stage population has a value of 3.5 and the fully grown larva was found to be 0.5 per seven plants for the posttreatment of the $2^{\text {nd }}$ application. In this case, the total larval population was 4.2 and the mean population of all the three instars was 1.4. The bifenthrin + emulsified neem oil combination treatment consisting of neem oil, NIFA adjuvant and bifenthrin as synergist has total neonate post-treatment population of 2.1, and middle and fully grown instar population of 4.2 and 1 respectively. The total larval count for this treatment was 7.3 and the mean value of all the instars was 2.4 . The neem biopesticide which was emulsified neem oil treatment has the neonate population of 2.3 , middle and fully grown instars population of 3.2 and 0.4 respectively. The total and

Table 3: Pretreatment and post-treatment larval population of pod borer after $2^{\text {nd }}$ spray.

\begin{tabular}{ccccccccccc}
\hline S. No & \multicolumn{3}{c}{ Larval Population (Pretreatment) } & \multicolumn{4}{c}{ Larval Population (Post-Treatment) } \\
\hline Treatments & $\mathrm{N}$ & $\mathrm{M}$ & $\mathrm{F}$ & Total & Mean & $\mathrm{N}$ & $\mathrm{M}$ & $\mathrm{F}$ & Total & Mean \\
\hline $\mathrm{T} 1$ & $0.9 \pm 0.36 \mathrm{ab}$ & $0.2 \pm 0.18 \mathrm{c}$ & $0 \pm 0 \mathrm{~b}$ & 1.1 & 0.36 & $0.4 \pm 0.2 \mathrm{c}$ & $2.7 \pm 0.37 \mathrm{c}$ & $0.6 \pm 0.35 \mathrm{~b}$ & 3.7 & 1.23 \\
\hline $\mathrm{T} 2$ & $0.7 \pm 0.3 \mathrm{~b}$ & $0.6 \pm 0.34 \mathrm{c}$ & $0.2 \pm 0.18 \mathrm{ab}$ & 1.5 & 0.5 & $3 \pm 0.6 \mathrm{~b}$ & $4.9 \pm 0.7 \mathrm{~b}$ & $1 \pm 0.7 \mathrm{~b}$ & 8.9 & 2.96 \\
\hline $\mathrm{T} 3$ & $1.6 \pm 0.6 \mathrm{a}$ & $0.7 \pm 0.37 \mathrm{bc}$ & $0.1 \pm 0.14 \mathrm{~b}$ & 2.8 & 0.9 & $0.2 \pm 0.1 \mathrm{c}$ & $3.5 \pm 0.6 \mathrm{bc}$ & $0.5 \pm 0.18 \mathrm{~b}$ & 4.2 & 1.4 \\
\hline $\mathrm{T} 4$ & $0.6 \pm 0.26 \mathrm{~b}$ & $1.4 \pm 0.31 \mathrm{ab}$ & $0.3 \pm 0.16 \mathrm{ab}$ & 2.3 & 0.76 & $2.1 \pm 0.33 \mathrm{bc}$ & $4.2 \pm 0.31 \mathrm{bc}$ & $1 \pm 0.62 \mathrm{~b}$ & 7.3 & 2.4 \\
\hline T5 & $0.8 \pm 0.29 \mathrm{ab}$ & $0.7 \pm 0.28 \mathrm{bc}$ & $0.1 \pm 0.1 \mathrm{~b}$ & 1.6 & 0.53 & $2.3 \pm 0.46 \mathrm{bc}$ & $3.2 \pm 0.38 \mathrm{bc}$ & $0.4 \pm 0.24 \mathrm{~b}$ & 5.9 & 1.96 \\
\hline T6 & $1.4 \pm 0.4 \mathrm{ab}$ & $1.7 \pm 0.29 \mathrm{a}$ & $0.6 \pm 0.3 \mathrm{a}$ & 3.7 & 1.23 & $11.5 \pm 2.6 \mathrm{a}$ & $15.5 \pm 1.6 \mathrm{a}$ & $5.1 \pm 1.4 \mathrm{a}$ & 32.1 & 10.7
\end{tabular}

Where, $\mathrm{N}=$ neonate, $\mathrm{M}=$ middle and $\mathrm{F}=$ fully grown larval stages respectively

The post-treatment larval population data was conducted after one, two and three days of the application. It can be seen from the Table 3 that emamectin treatment has a low population of neonate instar and has a value of 0.4 , and the population of the middle (M) instar was 2.7 per seven plants while the fully grown larvae have a population density of 0.6 . So the total larval population of all the instars of the pod borer was 3.7 and their mean was 1.23 after the application of the $2^{\text {nd }}$ spray. The acetamiprid treated plot has a greater population of the neonate larvae than that of emamactin and has a value of 3 and the middle instar population of 4.9 and the fully mature larval population of 1 respectively. It can be seen from Table 3 that total post-treatment larval population for all the three instars of the pod borer was 8.9 and the mean larval population values for this treatments were 5.9 and 1.96 respectively. The largest population of neonates was 11.5 in case of control group while the middle (M) and full grown instars have the population of 15.5 and 5.1 respectively. The total larval population for emamactin, acetamiprid, chlorpyrifos, bifenthrin + emulsified neem oil combination, emulsified neem oil and control were3.7, $8.9,4.2,7.3,5.9$ and 32.1 respectively and their mean was $1.23,2.96,1.4,2.4,1.96$ and 10.7 respectively.

The results obtained after the application of pesticides show that all the pesticide treatments have a greater effect on the control of larvae of the chickpea pod borer than the control. All the six treatments have almost the same number of larval instar before the treatment of the first spray. The first larval population was observed in the 
first week of April. The neonate, which is the first instar was present in all the observed subplots, and the middle instar which is formed by the conversion of neonate instar was observed only in the bifenthrin + emulsified neem oil combination and control treatments before the application and has a value of 0.2 each for both the treatments. The fully grown instar $(F)$ was absent an all the pretreatments plots. After the application of the pesticides, it was found that emamactin has the highest effect on the control of the chickpea pod borer larvae. \% reduction in the larval population was 63 after the first spray. bifenthrin + emulsified neem oil combination and emulsified neem oil treatments have an almost tTreatmenthe same effect on the control of pod borer larvae and \% reduction in case of this two treatment was 60 in each. The chlorpyrifos has the larval \% reduction of 56.4 while acetamiprid was the least effective treatment for the control of pod borer larvae after the application of the first spray. The \% reduction in the larval population was more pronounced after the application of the $2^{\text {nd }}$ spray. Table 4 shows that emamactin has the lowest control of pod borer larvae and the $\%$ reduction in the larvae was 88 . The chlorpyrifos showed the second best results after emamactin and the $\%$ reduction in the larval population, in this case, was reported to be 86.9. The bio-pesticide showed $81 \%$ reduction in the larval population of pod borer. The bifenthrin + emulsified neem oil combination treatment which was almost the same as that of emulsified neem oil treatment after $1^{\text {st }}$ spray showed a decreased efficacy as compared to emulsified neem oil treatment in lowering the larval population and showed a \% reduction of 77 . Acetamiprid was the least effective in controlling the larval population after the $2^{\text {nd }}$ spray and the total \% reduction was noted to be 72 .

Table 4: Percent reduction of the chickpea pod borer larvae after each spray.

\begin{tabular}{ccc}
\hline Treatments & \% Reduction (1 st $^{\text {spray })}$ & \% Reduction $\left(\mathbf{2}^{\text {nd }}\right.$ spray) \\
\hline T1 & 63 & 88 \\
\hline T2 & 42.3 & 72 \\
\hline T3 & 56.4 & 86.9 \\
\hline T4 & 60 & 77 \\
\hline T5 & 60 & 81 \\
\hline T6 & & \\
\hline
\end{tabular}

Percent Pod Damage and Pod Damage Reduction
The percent damage of pod for each treatment is shown in Table 5. The highest pod damage was observed in control, while the lowest value was observed in case of emamactin with a pod damage \% age of 13.33 the chlorpyrifos treatment showed a pod damage of 14 percent while the emulsified neem oil has a percent reduction of 14.66. In the case of pesticide treatments, acetamiprid has the highest pod damage after the control and the percent pod damage reported was 17.33 percent. Similarly, the highest pod damage reduction over control was also noted in the case of emamactin application and the lowest value was observed in the case of acetamiprid having values of $44.4 \%$ and 27.7 percent. The neem oil has $38.8 \%$ damage reduction while bifenthrin + emulsified neem oil combination has a \% age damage pod reduction of 30.5 .

Table 5: Percent pod damage and percent reduction of pod damage over control.

\begin{tabular}{ccc}
\hline Treatments & \% Damage pod & $\begin{array}{c}\text { \% Reduction in pod } \\
\text { Damage over } \\
\text { control }\end{array}$ \\
\hline $\mathrm{T} 1$ & $13.33 \mathrm{~b}$ & 44.4 \\
\hline $\mathrm{T} 2$ & $17.33 \mathrm{ab}$ & 27.7 \\
\hline $\mathrm{T} 3$ & $14 \mathrm{~b}$ & 41.66 \\
\hline $\mathrm{T} 4$ & $16.66 \mathrm{ab}$ & 30.5 \\
\hline $\mathrm{T} 5$ & $14.66 \mathrm{~b}$ & 38.8 \\
\hline $\mathrm{T} 6$ & $24 \mathrm{a}$ & - \\
\hline
\end{tabular}

\section{Grain Yield}

The grain yield obtained after the harvest of the chickpea plant are shown in Table $\mathbf{6}$. The highest grain yield was obtained for emamactin and the percent increase over the control was recorded to be 47.8 percent. The emulsified neem oil treatment yield was second after emamactin and was $22.5 \mathrm{~kg}$ and the percent increase was noted to be 40.6. The yield of grain was recorded for control and was $16 \mathrm{~kg}$ only. Suneel Kumar used emamactin against the chickpea pod borer and found that emamactin has $83.7 \%$ control over the control. Patel et al. found that emamectin showed a better activity against the chickpea pod borer ${ }^{15}$ and Singh and Yadav found the lowest pod damage 12.5 percent in chickpea in case of indoxacarb ${ }^{16}$. Jawad et al. observed that neem oil possessed almost the same 
Table 6: Bio-mass and grain yield of chickpea for all treatments.

\begin{tabular}{cccc}
\hline Treatments & Bio-mass $(\mathrm{kg})$ & Grain Yield $(\mathrm{kg})$ & \% increase in grain over control \\
\hline T1 & $90.5 \mathrm{a}$ & $23.66 \mathrm{a}$ & 47.8 \\
\hline $\mathrm{T} 2$ & $79 \mathrm{c}$ & $19.7 \mathrm{ab}$ & 23 \\
\hline T3 & $81.5 \mathrm{bc}$ & $20.33 \mathrm{a}$ & 27 \\
\hline T4 & $85 \mathrm{abc}$ & $21.8 \mathrm{a}$ & 36.2 \\
\hline T5 & $88 \mathrm{ab}$ & $22.5 \mathrm{a}$ & 40.6 \\
\hline T6 & $67 \mathrm{~d}$ & $16 \mathrm{~b}$ & \\
\hline
\end{tabular}

activity against the $H$. armigera on tomato vegetables ${ }^{17}$. They noticed that mean larval of pod borer per plant were 0.40 and 0.46 for neem and emamectin treatments respectively. Rajput et al. reported that synthetic insecticide was found to be the best treatment as compared to natural products ${ }^{18}$. Gohokar et al. found that neem treatments gave best results than synthetic insecticides ${ }^{19}$. Gilani noted that neem oil possesses repellent, insecticide and anti-feeding characteristics ${ }^{20}$. Singh and Kumar reported that emamectin was the effective insecticide in lowering the population of $H$. armigera in chickpea ${ }^{21}$. Sontakke et al. found that emamectin benzoate was found effective in decreasing the population of fruit borer and fruit damage in okra as well as tomato crops ${ }^{22}$. Neem oil showed a tremendous antifeedant, insecticidal and insect growth regulatory properties $^{23}$. In one study, it was found that Bollcure fraction and NSKE was highly effective and economical in lowering the $H$. armigera larvae in chickpea ${ }^{24}$.

\section{CONCLUSIONS}

The bio-pesticide of neem oil showed better results in controlling the pod borer larval population next to chlorpyrifos and emamectin after the $2^{\text {nd }}$ spray. The highest grain yield was reported for emamactin followed by emulsified neem oil treatment. Pakistan is the $3^{\text {rd }}$ largest producer of chickpea and there is need to use the bio-pesticide due to WTO constraints for the exportoriented agro-product and neem oil has proved to be a good bio-pesticide. This product is purely organic and a prominent candidate as a pesticide in organic farming. This product has been used effectively in controlling the aphid and potato leafhopper control. Further study is recommended on further crops and a pest to study the effect of the biopesticide.

\section{Acknowledgement}

The author is highly grateful to Mr. Alamzeb, Deputy Chief Scientist of the plant protection division of Nuclear Institute for Food and Agriculture, Peshawar for providing useful information for calculating the larval population of the chickpea pod borer.

\section{REFERENCES}

1. Ahmed K, Awan MS. Integrated management of insect pests of chickpea Cicer arietinum (L.) Walp. in South Asian Countries: Present status and future strategies a review. Pak J Zool. 2013; 45: 1125-45.

2. Ahmed S, Zia K, Shah N. Validation of chemical control of gram pod borer, Helicoverpa armigera (Hubner) with new insecticides. Intern J Agri Bio (Pakistan). 2004; 6(6): 978-80.

3. Sharma OP, Bhosle BB, Kamble KR, Bhede BV, Seeras NR. Management of pigeon pea pod borers with special reference to pod fly (Melanagromyza obtusa). Ind J Agri Sci. 2011; 81(6): 539-43.

4. Yadav NK, Singh PS. Field evaluation of some new insecticide molecules against pod borers in mung bean. Indian J Entomol. 2013; 75(4): 360-1.

5. Vinoth KB, Kumaran N, Kubendran D, Kuttalam S. Bio-efficacy of Flubendiamide+Thiacloprid 480 SC against insect pests of tomato. Pestol. 2010; 34(1): 44-7.

6. Pandey BM, Tripathi MK, Lakshmi V. Seasonal incidence of Gram pod borer, $H$. armigera (Hub.) On chickpea in Varanasi area. J Exp Zool 2012; 15(2):667-9.

7. Sreekanth M, Lakshmi MSM, Koteswar RY. Bioefficacy and economics of certain new insecticides against gram pod borer, $H$. armigera (Hubner) infesting pigeon pea (Cajanus cajan L.). Intern J Plant Ani Environ Sci. 2014; 4(1): 11-5. 
8. Singh $\mathrm{P}$, Singh $\mathrm{R}$, Kumar $\mathrm{S}$, Kumar $\mathrm{V}$, Kumar $\mathrm{S}$. Bioefficacy of certain new insecticides against the larval population of gram pod borer, $\mathrm{H}$. armigera (Hubner) in chickpea. The Ecoscan. VII: 2015; 315-8.

9. Kambrekar DN, Somanagouda G, Basavarajappa MP, Halagalimath SP. Effect of different dosage of emamectin benzoate 5 SG and indoxacarb 14.5 SC on pod borer $H$. armigera infesting chickpea. Legume Res 2012; 35(1): 13-7.

10. Sarwar M. Competency of natural and synthetic chemicals in controlling gram pod borer, $\mathrm{H}$. armigera (Hubner) on chickpea. Inter J of Agri Sci. 2012; 2(4): 132-5.

11. Meena LK, Raju SVS. Bio-efficacy of newer insecticides against tomato fruit borer, $\mathrm{H}$. armigera (Hubner) on tomato, Lycopersicon esculentum mill under field conditions. The Bioscan 2014; 9(1): 34750.

12. Hosamani AC, Bheemana M, Vinod SK, Rajesh L. Bio-efficacy of chlorantraniliprole $20 \mathrm{SC}$ (rynaxypyr) against $\mathrm{H}$. armigera of chickpea. Ind J Plant Protec. 2013;41(2): 178-79.

13. Kumar J. Neem oil content and its chemical constituents in relation to the agro-ecological factors and regions in India. Pestici Res J. 2010; 9:216-25.

14. Hossain A, Haque A, Ahmad M, Prodhan MZH. Development of an Integrated Management Approach for Pod Borer, H. armigera (Hubner) on Chickpea Bangladesh. J Agril Res. 2010; 35(2):201-6.

15. Patil SK, Ingle MB, Jamadagni BM. Bio-efficacy and economics of insecticides for management of $H$. armigera (Hubner) in chickpea. Ann Plant Protec Sci. 2007; 15(2): 307-11.
16. Singh SS, Yadav SK. Comparative efficacy of insecticides, bio-pesticides and neem formulations against $H$. armigera (Hubner) on chickpea. Ann Plant Protec Sci. 2007; 15(2): 299-302.

17. Shah JA, Inayatullah M, Sohail K, Shah SF, Shah S, Iqbal $\mathrm{T}$ et al. Efficacy of botanical extracts and a chemical pesticide against tomato fruit worm, Helicoverpa armigera (Lepidoptera: Noctuidae). Sarhad J of Agri 2013; 29(1): 93-6.

18. Rajput AA, Sarwar M, Bux M, Toufiq M. Evaluation of synthetic and some plant origin insecticides against Helicoverpa armigera (Hubner) on chickpea Pak J Biol Sci. 2003; 6 (5): 496-9.

19. Gohokar RT, Thakre SM, Borle MM. Chemical control of gram pod borer (Heliothis armigera Hubner) by different synthetic pyrethroid and insecticides. Pesticides 1987; 21 (11): 55-6.

20. Gilani G. Neem the wonder tree. In farming, Oct- Nov. Ed: M.T. Saleem, SAFE Foundation 2001; 27-30.

21. Singh AK, Kumar A. Evaluation of new molecules in SIPM modules against Helicoverpa armigera (Hubner) in chickpea, Ann PI Protec Sci. 2012; 20 (1): 19-23.

22. Sontakke BE, Das N, Panda PK, Swain LK. Bio efficacy of emamectin benzoate $5 \%$ SG against fruit and shoot borer in okra, Ann PI Protec Sci. 2007; 4, 2: 30-3.

23. Ramya $S$, Jayakumararaj $R$. Antifeedant activity of selected ethnobotanicals used by tribals of Vattal Hills on $H$. armigera (Hübner). J Pharmacol Res 2009; 2:1414-8.

24. Reghuraman M, Birah A, Gupta GP. Management of $H$. armigera in chickpea with botanical formulations. Ind J Entomol 2008; 70 (2): 118-22. 